\title{
ROCHAS SILICÁTICAS PORTADORAS DE POTÁSSIO COMO FONTES DO NUTRIENTE PARA AS PLANTAS SOLO ${ }^{(1)}$
}

\author{
Luciano da Silva Ribeiro ${ }^{(2)}$, Anacleto Ranulfo dos $\operatorname{Santos}^{(3)}$, Luiz \\ Francisco da Silva Souza ${ }^{(4)}$ \& Jamile Santana Souza ${ }^{(5)}$
}

\begin{abstract}
RESUMO
O objetivo deste trabalho foi avaliar, em casa de vegetação, o efeito da aplicação de pó de rochas silicáticas portadoras de K (ultramáfica alcalina, brecha piroclástica e flogopitito) na liberação de $\mathrm{K}$ e sobre outros atributos químicos do solo. Foi utilizado um Latossolo Amarelo distrófico coeso com teor de $\mathrm{K}$ de $0,03 \mathrm{cmol}_{\mathrm{c}} \mathrm{dm}^{-3}$ de solo. As rochas foram testadas sem e com correção da acidez do solo - neste caso, elevando o valor da saturação por bases para 70 \%. Inicialmente, as rochas e o corretivo de acidez foram aplicados e incorporados aos solos de cada vaso com $3 \mathrm{~kg}$ de solo, deixando-os em incubação por um período de 45 dias, com a umidade em torno de $80 \%$ da capacidade de campo. Foram testadas as doses equivalentes a $75,150,225$ e $300 \mathrm{~kg} \mathrm{ha}^{-1} \mathrm{~K}_{2} \mathrm{O}$ de todas as rochas e do $\mathrm{KCl}$, usado como fonte de referência. Findo o período de incubação, foi realizado um plantio de soja com a finalidade de observar a dissolução das rochas em um ambiente com plantas. As plantas foram colhidas 50 dias depois do plantio. Foram feitas análises do solo após o período de incubação e depois do plantio da soja. As rochas ultramáfica alcalina e brecha piroclástica foram as que mais liberaram $\mathrm{K}$ para o solo; a correção da acidez não influenciou o processo de dissolução das rochas.
\end{abstract}

Termos de indexação: pó de rocha, fertilizantes naturais, fertilizantes potássicos.

\footnotetext{
(1) Parte da Dissertação de Mestrado do primeiro autor. Recebido para publicação em julho de 2007 e aprovado em março de 2010.

(2) Engenheiro-Agrônomo Banco do Nordeste - BNB. Rua 31 de Maio s/n, CEP 46880-000 Itaberaba (BA). E-mail: lucianosr@bnb.gov.br

(3) Professor CCAAB, Universidade Federal do Recôncavo da Bahia - UFRB. CEP 44380-000 Cruz das Almas (BA). E-mail: anacleto@ufrb.edu.br

(4) Pesquisador da Embrapa Mandioca e Fruticultura Tropical. Rua Embrapa s/n, CEP 44380-000 Cruz das Cruz das Almas (BA). E-mail: lfranc@cnpmf.embrapa.br

(5) Bolsista Fapesb. E-mail: milinhass@yahoo.com.br
} 


\title{
SUMMARY: POTASSIUM-RICH SILICATE ROCKS AS PLANT NUTRIENT SOURCES
}

\begin{abstract}
This greenhouse study evaluated the effect of potassium-rich silicate rocks (alkaline ultramaphic, pyroclastic breccia and phlogopite) on the release of $K$ and other chemical nutrients of the soil. A Yellow Latossol with $0.03 \mathrm{cmol}_{c} \mathrm{dm}^{-3} \mathrm{~K}$ soil was used in the study. The rocks were tested at doses of $75,150,225$ and $300 \mathrm{~kg} \mathrm{ha}^{-1} \mathrm{~K}_{2} \mathrm{O}$ with and without lime, applied to increase the soil base saturation ( $V$-value) to $70 \%$. The rock and lime materials were mixed with the soil in the pots, watered to $80 \%$ of the soil field capacity and incubated for 45 days. An additional pot containing soil and $\mathrm{KCl}$, the reference $\mathrm{K}$ source, was also incubated. After incubation, soybean was sown to evaluate the effect of rock dissolution in a cultivation environment. Plants were harvested 50 days after sowing. Potassium was released in greatest amounts to the soil from ultramafic alkaline and pyroclastic breccia. Liming did not influence the rock dissolution process and K release.
\end{abstract}

Index terms: rock powder; natural fertilizers; potassic fertilizers.

\section{INTRODUÇÃO}

As rochas silicáticas normalmente contêm nutrientes de plantas em quantidades e disponibilidades que variam em função dos minerais presentes nas rochas. Por essa razão, essas rochas têm sido objeto de estudos visando avaliar seus potenciais como fontes alternativas para o suprimento nutricional às plantas.

Os teores insuficientes de potássio (K) disponível na maioria dos solos brasileiros contrastam com as elevadas exigências desse nutriente pelas culturas, 0 que tem proporcionado grande aumento de consumo de adubos potássicos para atender ao crescimento da agricultura brasileira nesses últimos anos (Nachtigall \& Raij, 2005). Os teores de K total nos solos do Brasil variam de 0,05 a 2,5\% (Lopes, 1982), ocorrendo maiores teores desse nutriente em solos menos intemperizados. Melo et al. (2004), estudando o potencial da liberação de $\mathrm{K}$ de um Latossolo e um Nitossolo originados de basalto no Rio Grande do Sul, verificaram que eles contêm pequenas quantidades de minerais primários, na forma de mica e feldspatos, fontes de K não trocável, além de esmectita hidroxientrecamadas, que são minerais secundários, como fonte potencial para liberação de K.

No Brasil, estudos com o K têm despertado interesse, visto que 85 \% do que é consumido no País tem sido importado. Dentre as fontes de K, destacase o cloreto de potássio $(\mathrm{KCl})$ como principal produto de importação. Segundo Lopes (2005), a única fonte produtora de fertilizantes potássicos no Brasil é o complexo de Mina/Usina de Taquari-Vassouras, em Sergipe, que vem sendo explorado pela Companhia Vale do Rio Doce desde o final de 1991.

$\mathrm{O}$ conhecimento da mineralogia e das formas de $\mathrm{K}$ nos solos, em conjunto com outros atributos, pode contribuir para melhor predição do suprimento, fixação e disponibilidade desse nutriente para as plantas. $\mathrm{O} \mathrm{pH}$, por exemplo, é um dos fatores que controlam a dissolução de minerais (Drever, 1994; Stillings \& Brantley, 1995). Segundo Blum \& Lasaga (1988), o papel do pH na dissolução dos minerais está relacionado com a adsorção dos íons $\mathrm{H}^{+} \mathrm{e} \mathrm{OH}^{-}$nas superfícies minerais, nas quais a hidrólise é controlada pelas reações ácido-base e pelas ligações oxigêniometal.

Os principais minerais ligados à disponibilidade de K nos solos brasileiros são os feldspatos potássicos, micas, vermiculitas e esmectitas (Curi et al., 2005).

Na nutrição mineral de plantas e, particularmente, na cultura da soja, o K assume posição de importância, destacando-se como um dos macronutrientes mais absorvidos e exportados pela cultura (Bataglia \& Mascarenhas, 1977; Rosolem, 1980). A importância do K para a soja deve-se à sua função na formação dos nódulos e ao aumento no teor de óleo nas sementes, beneficiando ainda a germinação, o vigor e a qualidade (Mascarenhas et al., 2000).

O objetivo deste trabalho foi avaliar, em casa de vegetação, o efeito da aplicação de pó de rochas silicáticas portadoras de K no fornecimento desse nutriente e sobre outros atributos químicos do solo.

\section{MATERIAL E MÉTODOS}

Foi utilizada uma amostra de Latossolo Amarelo distrófico coeso, representativo dos Tabuleiros Costeiros, coletada em Cruz das Almas (BA), onde o clima, segundo Köppen, é uma transição entre os tipos Am e Aw, apresentando de dois a três meses de seca ao ano e pluviosidade média anual de $1.244 \mathrm{~mm}$ (Embrapa, 1993). As amostras de solo foram coletadas na profundidade de 0 a $20 \mathrm{~cm}$ e apresentaram, de acordo com análises químicas, $0,4 \mathrm{mg} \mathrm{dm}^{-3} \mathrm{de} \mathrm{P} ; 0,03$, 0,4, 0,4, 0,5 e 2,53 $\mathrm{cmol}_{\mathrm{c}} \mathrm{dm}^{-3}$ de K, $\mathrm{Ca}, \mathrm{Mg}, \mathrm{Al} \mathrm{e} \mathrm{H}+\mathrm{Al}$, respectivamente; e 5,97 $\mathrm{g} \mathrm{kg}^{-1}$ de matéria orgânica. 
O trabalho foi conduzido em casa de vegetação, envolvendo o cloreto de potássio como fonte de referência de $\mathrm{K}$ e pó de rochas com diversos teores do nutriente. Todas as rochas utilizadas foram moídas e peneiradas, usando a porção com granulometria inferior a $0,3 \mathrm{~mm}$ para a análise do teor de $\mathrm{K}_{2} \mathrm{O}$ e para os ensaios experimentais. As rochas utilizadas foram: flogopitito (coletado na Bahia, com 5,73 \% de $\mathrm{K}_{2} \mathrm{O}$ ), ultramáfica alcalina (coletada em Santa Catarina, com 2,79\% de $\mathrm{K}_{2} \mathrm{O}$ ) e brecha piroclástica (coletada em Goiás, com 1,69 \% de $\mathrm{K}_{2} \mathrm{O}$ ). De acordo com Resende et al. (2006a), a ultramáfica alcalina é composta por minerais Ferromagnesianos (olivina), piroxênio, feldspato, carbonato e flogopita, e a brecha, por flogopita, zeólita e feldspatoides.

As rochas foram testadas sem correção e com correção da acidez do solo - neste caso, elevando o valor da saturação por bases (V) para $70 \%$. Como corretivo, foi utilizado calcário dolomítico de alta velocidade de reação (100 \% passando na peneira de $50 \mathrm{mesh}$ ). Inicialmente, as rochas e o corretivo de acidez foram aplicados e incorporados ao solo de cada vaso (3 kg/vaso de solo), deixando-os em incubação por um período de 45 dias, com a umidade em torno de $80 \%$ da capacidade de campo.

Foram avaliadas as doses de 37,$5 ; 75 ; 112,5$; e $150 \mathrm{mg} \mathrm{kg}^{-1}$ de $\mathrm{K}_{2} \mathrm{O}$ no solo (equivalentes a $75 ; 150$; 225 e $300 \mathrm{~kg} \mathrm{ha}^{-1} \mathrm{~K}_{2} \mathrm{O}$ ) para o cloreto de potássio e para as três rochas consideradas, com e sem correção da acidez, totalizando 32 tratamentos em um esquema fatorial $4 \times 4 \times 2$. O delineamento experimental foi inteiramente casualizado com quatro repetições.

Finalizado o período de incubação, a massa de solo de cada vaso (3 kg/vaso) foi espalhada e homogeneizada sobre uma lona plástica, para retirada de amostras para análises químicas.

Iniciou-se em seguida uma etapa com o cultivo de soja, com a finalidade de observar o comportamento dessas rochas na presença de plantas. Mantiveramse cinco plantas da leguminosa por vaso após o desbaste. Por ocasião do plantio da soja, todos os vasos receberam uma adubação uniforme com $\mathrm{P}\left(65 \mathrm{mg} \mathrm{kg}^{-1}\right.$ $\mathrm{P}_{2} \mathrm{O}_{5}$ de solo), $\mathrm{S}$ (40 $\mathrm{mg} \mathrm{kg}^{-1} \mathrm{~S}$ de solo) e micronutrientes ( $\mathrm{Zn}, \mathrm{Cu}, \mathrm{Fe}$ e B, respectivamente nas doses de 2,0; 1,5; 2,0; e $0,7 \mathrm{mg} \mathrm{kg}^{-1}$ de solo). O K solúvel (KCl) e os demais nutrientes foram aplicados na forma líquida, a partir de soluções das seguintes fontes: fosfato de cálcio, sulfato de magnésio, cloreto de $\mathrm{Zn}$, sulfato de $\mathrm{Cu}$, sulfato $\mathrm{Fe}$ e ácido bórico.

A colheita da parte aérea da soja foi feita 50 dias após o plantio, no estádio R2, que corresponde ao período de floração plena e ao período de maior acúmulo de K na parte aérea da soja (Borkert et al., 2005). Após a colheita foram coletadas novas amostras de solo, para análises químicas, conforme Embrapa (1997). Os dados obtidos foram submetidos a testes de média e análise de regressão por meio do software estatístico SISVAR (Ferreira, 1999).

\section{RESULTADOS E DISCUSSÃO}

\section{Liberação do K das rochas para o solo}

A incubação do solo com as rochas ultramáfica alcalina e brecha piroclástica resultou em efeito positivo e linear sobre o K trocável do solo, ou seja, quanto maiores as doses de $\mathrm{K}_{2} \mathrm{O}$ aplicadas, maiores foram as concentrações do $\mathrm{K}$ trocável, o que não ocorreu com o flogopitito (Figura 1a). Esses resultados evidenciam maior facilidade de liberação do K nas duas primeiras rochas, em comparação ao flogopitito, que não teve efeito significativo sobre o K do solo.

Lopes-Assad et al. (2006) associaram esse comportamento a diferenças nas composições mineralógicas das rochas ultramáfica alcalina e flogopitito, visto que a segunda é uma rocha praticamente monominerálica, intimamente associada à ocorrência de esmeralda e formada pela mica flogopita com alto teor de sílica, enquanto a ultramáfica apresenta mineralogia muito complexa, possuindo, além da flogopita, outros minerais, como olivina, carbonatos e piroxênios, os quais lhe conferem uma solubilização mais rápida.

De acordo com Basset (1960), a alteração por troca iônica que ocorre nas micas é consequência da fixação do K na estrutura do mineral. Segundo esse autor, um dos fatores aceitos que têm importante influência na estrutura das micas é o desequilíbrio de carga negativa nas camadas devido às substituições nas posições tetraédricas e octaédricas.

Observou-se redução na concentração de K trocável no solo após o plantio da soja (Figura 1b), o que sugere que o $\mathrm{K}$ encontrado no solo, após o período de incubação, foi disponibilizado para as plantas. Essa

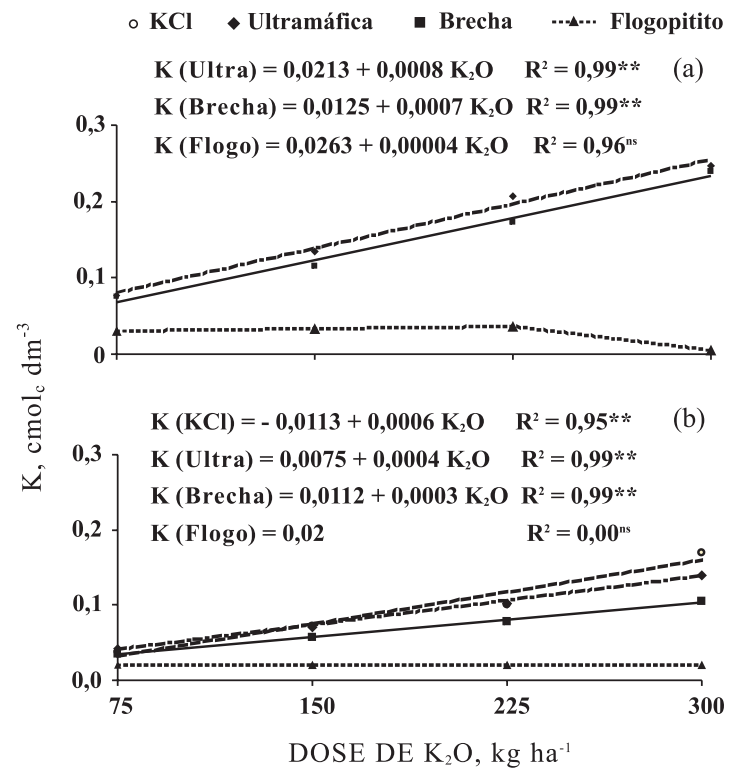

Figura 1. Potássio trocável no solo após 45 dias de incubação com pó de rochas silicáticas (a) e após cultivo de soja (b). 
redução nos teores de K pode ser observada na análise da regressão polinomial, uma vez que, mesmo mantendo-se o efeito linear positivo, o coeficiente linear e o coeficiente angular das regressões para estimativa do K trocável são menores após o plantio da soja, tanto para a rocha altramáfica alcalina como para a brecha piroclástica.

Em razão da elevada mobilidade do $\mathrm{K}$ no solo, o teor de $\mathrm{K}$ trocável utilizado isoladamente não representa, de maneira eficiente, a disponibilidade desse nutriente em solos com características mineralógicas, físicas e químicas distintas (Meurer \& Anghinoni, 1993).

Embora as rochas tenham sido testadas com e sem correção da acidez, a prática da calagem não apresentou efeito significativo na liberação de K pelas rochas. É provável que esse comportamento se deva à alta liberação de cálcio pela ultramáfica: $300 \%$ superior à da testemunha quando as rochas foram testadas sem correção da acidez e 17,5 \% quando a acidez foi corrigida (Quadro 1). A calagem promove o aumento da relação $(\mathrm{Ca}+\mathrm{Mg}) / \mathrm{K}$ do solo, podendo reduzir a absorção de $\mathrm{K}$ pelas raízes e provocar sua deficiência (Goedert et al., 1975).

Segundo Oliveira et al. (2001), a relação $(\mathrm{Ca}+\mathrm{Mg}) /$ $\mathrm{K}$ trocável no solo constitui um índice importante de avaliação da disponibilidade do K no solo para a cultura da soja. No entanto, Lima et al. (2001) verificaram que as doses de $\mathrm{K}$ utilizadas na adubação do feijoeiro não diminuíram os teores de $\mathrm{Ca}$ e $\mathrm{Mg}$ na parte aérea da planta.

\section{Liberação do $\mathbf{P}$ das rochas para o solo}

As rochas ultramáfica e brecha, além do suprimento de K, também disponibilizaram $\mathrm{P}$ para o solo, após o período de incubação (Figura 2); a ultramáfica apresentou valores superiores do nutriente para todas as doses avaliadas. Não se detectou influência do flogopitito nos teores de $\mathrm{P}$ no solo. A elevada liberação de $\mathrm{P}$ pelas duas rochas justificou a alta dose do nutriente aplicada para o plantio da soja. O procedimento teve efeito satisfatório, pois não houve diferença significativa para $\mathrm{P}$ disponível no solo entre os tratamentos avaliados após o plantio da cultura.

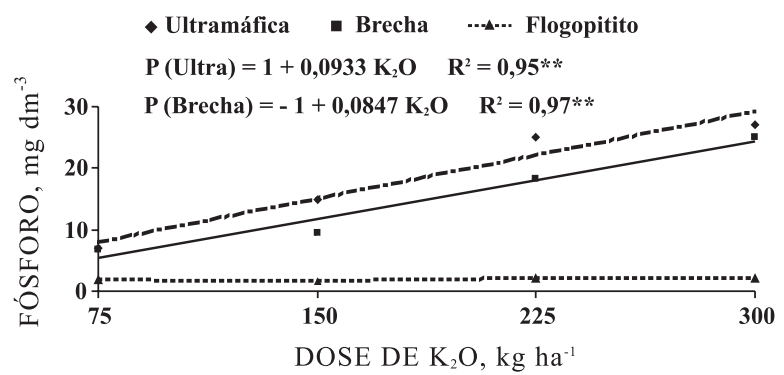

Figura 2. Fósforo disponível no solo após 45 dias de incubação com pó de rochas silicáticas portadoras de potássio.

Embora o teor total de $\mathrm{P}$ no solo possa variar de 100 a $1.000 \mathrm{mg} \mathrm{kg}^{-1}$ (Brady \& Weil, 1996), ou entre 200 e $3.000 \mathrm{mg} \mathrm{kg}^{-1}$ (Novais \& Smyth, 1999), menos de $0,1 \%$ desse total está presente na solução do solo, cujos valores variam entre 0,002 e $2,0 \mathrm{mg} \mathrm{L}^{-1}$ (Fardeau, 1996), o que é relativamente insuficiente para o desenvolvimento da maioria das culturas.

\section{pH do solo}

Todos os tratamentos promoveram aumentos significativos nos valores de $\mathrm{pH}$ em função da calagem (Quadro 2), porém, devido às características de correção de acidez da rocha ultramáfica, esta foi a que apresentou a menor diferença (14\%), seguida pela brecha (23\%), flogopitito (24\%) e $\mathrm{KCl}(35 \%)$, em relação ao $\mathrm{pH}$ do solo nos tratamentos sem correção.

Quadro 2. Valores do pH do solo após 45 dias de incubação com rochas silicáticas portadoras de potássio

\begin{tabular}{lrll}
\hline Tratamento & Sem calagem & Com calagem \\
\hline Testemunha & $4,89 \mathrm{bB}$ & $6,63 \mathrm{aA}$ \\
Ultramáfica & $5,85 \mathrm{aB}$ & $6,66 \mathrm{aA}$ \\
Brecha & $4,98 \mathrm{bB}$ & $6,15 \mathrm{bA}$ \\
Flogopitito & $4,93 \mathrm{bB}$ & $6,11 \mathrm{bA}$ \\
\hline
\end{tabular}

Médias seguidas de mesma letra, minúscula na coluna e maiúscula na linha, não diferem entre si pelo teste de Tukey a $5 \%$.

Quadro 1. Teores de cálcio e magnésio trocáveis no solo $\left(\mathrm{cmol}_{\mathrm{c}} \mathrm{dm}^{-3}\right)$ após 45 dias de incubação com rochas silicáticas portadoras de potássio

\begin{tabular}{|c|c|c|c|c|}
\hline \multirow{2}{*}{ Tratamento } & \multicolumn{2}{|c|}{$\mathrm{Ca}^{2+}$} & \multicolumn{2}{|c|}{$\mathrm{Mg}^{2+}$} \\
\hline & Sem calagem & Com calagem & Sem calagem & Com calagem \\
\hline & & 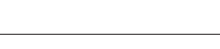 & & \\
\hline Testemunha & $0,375 \mathrm{bB}$ & $1,500 \mathrm{bA}$ & $0,638 \mathrm{aB}$ & $1,400 \mathrm{aA}$ \\
\hline Ultramáfica & $1,488 \mathrm{aB}$ & $1,763 \mathrm{aA}$ & $0,763 \mathrm{aB}$ & $1,075 \mathrm{bA}$ \\
\hline Brecha & $0,550 \mathrm{bB}$ & $1,200 \mathrm{cA}$ & $0,813 \mathrm{aB}$ & $1,413 \mathrm{aA}$ \\
\hline Flogopitito & $0,475 \mathrm{bB}$ & $1,100 \mathrm{cA}$ & $0,738 \mathrm{aB}$ & $1,025 \mathrm{bA}$ \\
\hline
\end{tabular}

Médias seguidas de mesma letra, minúscula na coluna e maiúscula na linha, não diferem entre si pelo teste de Tukey a 5 \%. 
Estudando a solubilização de pó de rocha pela ação do fungo Aspergilus niger, Lopes-Assad et al. (2006) verificaram redução drástica do $\mathrm{pH}$ nos primeiros sete dias de incubação nos tratamentos com ultramáfica alcalina e flogopitito; no entanto, na ultramáfica os valores voltaram a aumentar a partir desse período, o que não ocorreu com o flogopitito. Segundo esses autores, a elevação do $\mathrm{pH}$ na ultramáfica alcalina deve estar associada a uma liberação de bases contidas nos minerais dessas rochas, o que não ocorreu com o tratamento com flogopitito, em que prevaleceu o efeito acidificante do fungo.

\section{Saturação por bases}

De forma coerente com sua ação corretiva de acidez e com os teores de Ca (Quadro 1), a ultramáfica alcalina promoveu aumento significativo na saturação por bases, sobressaindo em relação às demais fontes, principalmente quando não houve a aplicação de calcário (Quadro 3). Com a aplicação de calcário, o valor da saturação por bases do tratamento com a ultramáfica alcalina não mostrou diferença significativa em relação ao $\mathrm{KCl}$ e à brecha piroclástica, porém os resultados foram superiores 7 e $8 \%$, respectivamente. Observa-se, na comparação entre as quatro fontes de $\mathrm{K}$ testadas, que as menores saturações por bases ocorreram nos tratamentos com o flogopitito.

Pesquisas realizadas por Mendes et al. (2006a,b), Silva et al. (2006a,b) e Resende et al. (2006b) demonstraram que a ultramáfica alcalina tem se mostrado promissora para utilização em solos ácidos, liberando $\mathrm{Ke} \mathrm{Ca}$, podendo influenciar na absorção de outros nutrientes, como $\mathrm{Mg}$, Fe, Mn e Zn, resultando em benefícios para o desenvolvimento das plantas e funcionando como condicionador de solo.

\section{Sódio trocável no solo}

A rocha ultramáfica alcalina foi a que mais liberou Na para o solo, tanto na incubação (Figura 3a) quanto após o plantio da soja (Figura 3b), seguida pela brecha piroclástica, que apresentou valores, em média, $50 \%$ inferiores. O excesso de $\mathrm{Na}$ no solo pode levar a planta à morte por seca fisiológica, além de prejudicar a germinação de sementes.

Quadro 3. Saturação por bases do solo após o cultivo da soja com diferentes fontes de potássio

\begin{tabular}{lcc}
\hline Tratamento & Sem calagem & Com calagem \\
\hline & \multicolumn{2}{c}{ Saturação por bases (V \%) } \\
KCl & $43,875 \mathrm{bB}$ & $73,375 \mathrm{aA}$ \\
Ultramáfica & $69,250 \mathrm{aB}$ & $79,125 \mathrm{aA}$ \\
Brecha & $44,375 \mathrm{bB}$ & $72,000 \mathrm{aA}$ \\
Flogopitito & $38,125 \mathrm{bB}$ & $63,000 \mathrm{bA}$ \\
\hline
\end{tabular}

Médias seguidas de mesma letra, minúscula na coluna e maiúscula na linha, não diferem entre si pelo teste de Tukey a $5 \%$.

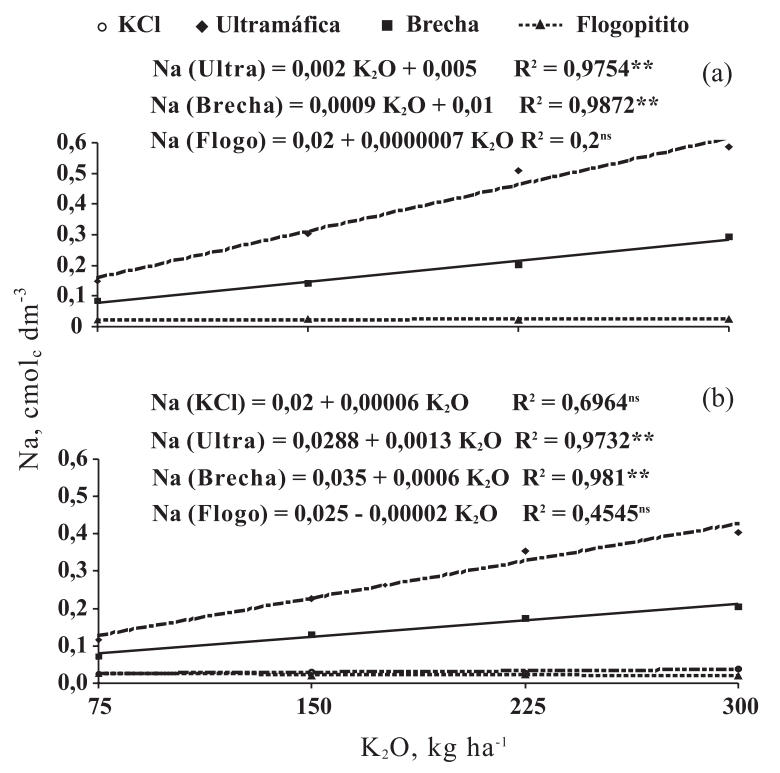

Figura 3. Sódio trocável no solo após incubação de 45 dias (a) e após cultivo de soja (b).

Sem a correção da acidez, os teores de Na liberados pelos tratamentos com as rochas ultramáfica alcalina e brecha piroclástica representaram entre 5 e $16 \%$ da soma de bases do solo, sempre aumentando com o aumento das doses, o que indica elevada contribuição do elemento nos valores da saturação por bases observados nesses tratamentos. Com a correção da acidez, o tratamento ultramáfica alcalina mantevese com o mesmo nível do elemento no complexo de troca, enquanto no tratamento brecha piroclástica o percentual foi reduzido para valores inferiores a $10 \%$.

Liberações de elementos não nutrientes também foram verificadas por Resende et al. (2006b) na rocha ultramáfica alcalina e devem ser objeto de estudo em pesquisas futuras, tendo em vista a possibilidade de sua utilização para a agricultura. O flogopitito e o $\mathrm{KCl}$ não mostraram efeito significativo sobre o Na do solo.

\section{CONCLUSÕES}

1. Entre as rochas estudadas, a ultramáfica alcalina e a brecha piroclástica promoveram as maiores liberações de K para o solo Latossolo Amarelo distrófico coeso, mostrando-se mais promissoras do que o flogopitito para uso agrícola como fonte do nutriente.

2. Além do potássio, as rochas ultramáfica alcalina e brecha piroclástica também disponibilizaram $\mathrm{P}$ para o solo.

3. A correção da acidez não influenciou a liberação de $\mathrm{K}$ e $\mathrm{P}$ pelas rochas estudadas.

4. A rocha ultramáfica alcalina destacou-se das demais no que diz respeito à correção da acidez do solo e, por consequência, na elevação da sua saturação por bases. 
5. Tanto a rocha ultramáfica alcalina como a brecha piroclástica apresentaram liberação de sódio para o solo, o que deve se constituir em objeto de avaliações complementares, em razão dos efeitos indesejáveis para solo e plantas causados por esse elemento.

\section{LITERATURA CITADA}

BASSET, W.A. Role of hidroxyl orientation in mica alteration. Geol. Soc. Am. B., 71:449-456, 1960.

BATAGLIA, O. \& MASCARENHAS, H.A.A. Absorção de nutrientes pela soja. Campinas, Instituto Agronômico de Campinas, 1977. 36p. (Boletim Técnico, 41)

BLUM, A. \& LASAGA, A. Role of surface speciation in low temperature dissolution of minerals. Nature, 331:432 433,1988

BORKERT, C.M.; CASTRO, C.; OLIVEIRA, F.A.; KLEPKER, D. \& OLIVEIRA JÚNIOR, A. O potássio na cultura da soja. In: YAMADA, T. \& ROBERTS, T.L., eds. Potássio na agricultura brasileira. Piracicaba, Associação Brasileira para a Pesquisa da Potassa e do Fosfato, 2005. p.671-722.

BRADY, N.C. \& WEIL, R.R. The nature and properties of soils. 11.ed. New Jersey, Prentice Hall, 1996. 727p.

CURI, N.; KÄMPF, N. \& MARQUES, J.J. Mineralogia e formas de potássio em solos do Brasil. In: YAMADA, T. \& ROBERTS, T.L., eds. Potássio na agricultura brasileira. Piracicaba, Associação Brasileira para a Pesquisa da Potassa e do Fosfato, 2005. p.71-92.

DREVER, J.I. The effect of land plants on weathering rates of silicate minerals. Geochim. Cosmochim. Acta, 58:23252332,1994

EMPRESA BRASILEIRA DE PESQUISA AGROPECUÁRIA . EMBRAPA. Centro Nacional de Pesquisa de Mandioca e Fruticultura Tropical (Cruz das Almas, BA). Levantamento detalhado dos solos do Centro Nacional de Pesquisa de Mandioca e Fruticultura Tropical - Cruz das Almas, Bahia. Cruz das Almas, 1993. 126 p. (Boletim de Pesquisa, 7).

EMPRESA BRASILEIRA DE PESQUISA AGROPECUÁRIA EMBRAPA. Centro Nacional de Pesquisa de Solos. Manual de método de análise de solo. 2.ed. Rio de Janeiro, 1997. 212p.

FANNING, D.S.; KERAMIDAS, V.Z. \& EL-DOSOKY, M.A Micas. In: DIXON, J. \& WEED, S., eds. Mineral in soil environments. Wisconsin, Soil Science Society of America, 1989. p.551-634.

FARDEAU, J.C. Dynamics of phosphate in soils. An isotopic outlook. Fert. Res., 45:91-100, 1996.

FERREIRA, D.F. Sistema para análise de variância para dados balanceados (SISVAR). Lavras, Universidade Federal de Lavras, 1999. 92p.

GOEDERT, W. J.; COREY, R.B. \& SYERS, J.K. The effects on potassium equilibria in soils of Rio Grande do Sul, Brazil. Soil Sci., 120:107-111, 1975.
LIMA, E.V.; ARAGÃO, C.A.; MORAIS, O.M.; TANAKA, R. \& GRASSI FILHO, H. Adubação NK no desenvolvimento e na concentração de macronutrientes no florescimento do feijoeiro. Sci. Agric., .58:125-129, 2001.

LOPES, A.S. Mineralogia do potássio em solos do Brasil. In: SIMPÓSIO SOBRE POTÁSSIO NA AGRICULTURA BRASILEIRA, 1982, Londrina. Anais... Piracicaba, Instituto da Potassa \& Fosfato, Instituto Internacional da Potassa, 1982. p.51-65.

LOPES, A.S. Reservas de minerais potássicos e produção de fertilizantes potássicos no Brasil. In: YAMADA, T. \& ROBERTS, T.L., eds. Potássio na agricultura brasileira. Piracicaba, Associação Brasileira para a Pesquisa da Potassa e do Fosfato, 2005. p.21-32.

LOPES-ASSAD, M.L.; ROSA, M.M.; ERLER, G. \& CECCATOANTONINI, S.R. Solubilização de pó-de-rocha por Aspergillus niger. Esp. Geogr., 9:1-17, 2006.

MASCARENHAS, H.A.A.; TANAKA, R.T.; CARMELLO, Q.A.C.; GALLO, P.B. \& AMBROSANO, G.M.B. Calcário e potássio para a cultura da soja. Sci. Agric., 57:445-449, 2000 .

MELO, G.W.; MEURER, E.J. \& PINTO, L.F.S. Fontes de potássio em solos distroférricos cauliníticos originados de basalto no Rio Grande do Sul. R. Bras. Ci. Solo, 28:597. 603,2004

MENDES, A.M.S.; SILVA, D.J.; FARIA, C.M.B. \& MORAIS, A.T. Potencial de rochas silicáticas no fornecimento de nutrientes para milheto: 1. Macronutrientes. In: REUNIÃO BRASILEIRA DE MANEJO E CONSERVAÇÃO DO SOLO E DA ÁGUA, 16., Aracaju, 2006. Anais... Aracaju, UFS/SBCS, 2006a. CD-ROM.

MENDES, A.M.S.; SILVA, D.J.; FARIA, C.M.B.; MORAIS, A.T.; SILVA, E.J. \& SILVA, E.A.R. Potencial de rochas silicáticas no fornecimento de micronutrientes para melão. In: REUNIÃO BRASILEIRA DE FERTILIDADE DO SOLO E NUTRIÇÃO DE PLANTAS, 27., Bonito, 2006. Anais. Dourados, Embrapa Agropecuária Oeste/SBCS, 2006b. CD-ROM. (Documentos, 82).

MEURER, E.J. \& ANGHINONI, I. Disponibilidade de potássio e sua relação com parâmetros de solo. R. Bras. Ci. Solo, 17:377-382, 1993.

NACHTIGALL, G.R. \& RAIJ, B.van. Análise e interpretação de potássio no solo. In: YAMADA, T. \& ROBERTS, T.L., eds. Potássio na agricultura brasileira. Piracicaba, Associação Brasileira para a Pesquisa da Potassa e do Fosfato, 2005. p.93-118.

NOVAIS, R.F. \& SMYTH, T.J. Fósforo em solo e planta em condições tropicais. Viçosa, MG, Universidade Federal de Viçosa, 1999. 399p

OLIVEIRA, F.A.; CARMELLO, Q.A.C. \& MASCARENHAS, H.A. A disponibilidade de potássio e suas relações com cálcio e magnésio em soja cultivada em casa de vegetação. Sci. Agric., 58:329-335, 2001.

RESENDE, A.V.; MARTINS, E.S.; OLIVEIRA, C.G.; SENA, M.C.; MACHADO, C.T.T.; KINPARA, D.I. \& OLIVEIRA FILHO, E.C. Suprimento de potássio e pesquisa de uso de rochas "in natura" na agricultura brasileira. Esp. Geog., 9:19-42, 2006a. 
RESENDE, A.V.; MACHADO, C.T.T.; MARTINS, E.S.; SENA, M.C.; NASCIMENTO, M.T.; SILVA, L.C.R. \& LINHARES, N.W. Rochas como fontes de potássio e outros nutrientes para culturas anuais. Esp. Geog., 9:135-161, 2006b.

ROSOLEM, C.A. Nutrição mineral e adubação da soja. Piracicaba, POTAFOS, 1980. 80p. (Boletim Técnico, 6)

SILVA, D.J.; FARIA, C.M.B.; MENDES, A.M.S. \& MORAIS, A.T. Potencial de rochas silicáticas no fornecimento de macronutrientes para soja. In: REUNIÃO BRASILEIRA DE MANEJO E CONSERVAÇÃO DO SOLO E DA ÁGUA, 16., Aracaju, 2006. Anais. Aracaju, UFS/SBCS, 2006a. CD-ROM.
SILVA, D.J.; FARIA, C.M.B.; MENDES, A.M.S. \& MORAIS, A.T. Potencial de rochas silicáticas no fornecimento de micronutrientes para soja. In: REUNIÃO BRASILEIRA DE MANEJO E CONSERVAÇ̃̃O DO SOLO E DA ÁGUA, 16., 2006, Aracaju. Anais. Aracaju, UFS/SBCS, 2006b. CD-ROM.

STILLINGS, L.L. \& BRANTLEY, S.L. Feldspar dissolution at $25{ }^{\circ} \mathrm{C}$ and $\mathrm{pH}$ 3.: Reation stichiometry and the effect at cations. Geochim. Cosmochim. Acta, 59:1483-1496, 1995. 